\title{
Outcome Analysis of Intra-Articular Scapula Fracture Fixation with Distal Radius Plate: A Multicenter Prospective Study
}

\author{
Ranajit Panigrahi, ${ }^{1,}{ }^{*}$ Divya Madharia, ${ }^{1}$ Dibya Singha Das, ${ }^{1}$ Saswat Samant, ${ }^{1}$ and Manas Ranjan Biswal ${ }^{1}$ \\ ${ }^{1}$ Department of Orthopedics, Hi-Tech Medical College \& Hospital, Bhubaneswar, India \\ "Corresponding author: Ranajit Panigrahi, Department of Orthopedics, Hi-Tech Medical College \& Hospital, Bhubaneswar, India. Tel: +91-9777037435, E-mail: \\ ranajitpanigrahi@gmail.com
}

Received 2016 January 23; Revised 2016 May 13; Accepted 2016 June 25.

\begin{abstract}
Background: Scapula fractures occur in approximately $1 \%$ of all fractures and constitute about $3 \%-5 \%$ of all injuries of the shoulder joint.

Objectives: This study aimed to evaluate the clinical outcomes of 20 surgically treated patients with displaced glenoid fractures after stabilization with distal radius plate.

Methods: Between 2012 and 2015, at 2 centers (HMCH \& SHCE) of Bhubaneswar Odisha, we stabilized 20 scapular intra-articular fractures surgically with distal radius locking plate and studied the outcome of the surgeries. The outcome of the 20 fractures was determined using the Constant and Murley score. Both shoulders were assessed and the score on the injured side was given as a percentage of that on the uninjured side.

Results: The median score was $88 \%$ (mean $65 \%$, range 30 to 100 ). The median score for strength was $21 / 25$ (mean 19 , range 0 to 25 ) and that for pain 11/15 (mean 11, range 5 to 15). The median functional score was 16/20 (mean 15, range 0 to 20). The mean range of active abduction of the shoulder was $135^{\circ}$ (20 to 180), the mean range of flexion $138^{\circ}$ (20 to 180) and the mean range of external rotation $38^{\circ}$ (0 to 100). Five patients showed excellent result; 11 patients showed good result; three patients showed fair result and one patient had poor outcome according to the Constant-Murley score. A superficial infection settled with antibiotics after operation in one patient whose score at final follow-up was $96 \%$. In one patient, delayed healing was reported because of infection. One patient with stiffness of the shoulder at six weeks underwent manipulation under anesthesia with a follow-up score of $81 \%$.

Conclusions: Various fixation modalities have been described in the literature, however fixation of intra-articular fracture of glenoid with distal radius locking plate for articular reconstruction in the presented series provides good functional outcome with early restoration of the range of motion of the shoulder.
\end{abstract}

Keywords: Scapula Fracture, Distal Radius Plate, Trauma Glenoid, Intra Articular Glenoid, Intra Articular Scapula, Fall From Height

\section{Background}

Scapula fractures occur in approximately $1 \%$ of all fractures and constitute about 3\% - 5\% of all injuries of the shoulder joint (1-3). Ten to forty percent of these involves scapular neck, and out of these, only $10 \%$ are displaced and indicative of operative intervention $(1,4-7)$. The most common mechanism of injury for scapular fractures is a direct and high energy violent impact, which frequently affects the body of the scapula. This violent force, which gets transmitted from the upper extremity to the scapula, has usually high energy (2). On the basis of the position of the arm and intensity of the impact at the time of the trauma, fractures of the glenoid surface may occur. Scapulae are well-protected by the nearby musculature; hence, displaced intra-articular fractures of the glenoid are rare fractures (8-10). However, with the increasing incidence of high-energy trauma, these types of fractures are no more rare in poly-trauma patients (11-15). Most of the scapular fractures are commonly treated satisfactorily with nonop- erative methods $(8,9,16,17)$. However, in few selected intraarticular scapular fractures, the best outcome is usually obtained with open reduction and internal fixation $(16,17)$. They are often associated with poly-trauma, which takes the immediate attention away from scapula and hence other life threatening injuries are treated first $(8,9)$. Surgical indications are there in the literature that include the unstable shoulder joint based on multiple disruptions of the superior shoulder suspensory complex (SSSC) (18-20), 'medialization of glenoid' (medial/lateral (M/L) displacement) by $10-25 \mathrm{~mm}(21,22)$, angular deformity $(21,22)$, shortening $>25 \mathrm{~mm}$ as defined by Jones et al. (22) (a measure of medialization of the glenoid), displaced fracture of the glenoid with intra-articular step-off or gap between 2 and $10 \mathrm{~mm}$, and $20 \%-30 \%$ involvement of the articular surface or instability of the glenohumeral joint(4, 7, 23-25). There are many published papers that describe different operative approaches and fixation techniques for scapula fractures $(7,24,25)$. Ideberg's classification (3) is the most 
common classification used for scapular fractures. Combination fractures like that of a scapular neck fracture and a clavicular fracture making a floating shoulder $(18,26)$. The fixation of any of the two fractures is necessary to stabilize the shoulder joint. In these cases, the above-mentioned criteria for scapula fracture fixation will help in deciding that which fracture should be treated surgically.

\section{Objectives}

This study aimed to evaluate the clinical outcomes of 20 surgically treated patients with displaced glenoid fractures after stabilization with distal radius plate.

\section{Methods}

Between 2012 and 2015, at 2 centers (HMCH \& SHCE) of Bhubaneswar Odisha, we stabilized 20 scapular intraarticular fractures surgically with distal radius locking plate and studied the outcome of the surgeries. From a total of 20 patients, 5 were females and 15 were males having a mean age of 32 years (age range, 20 to 75 ). All had a displaced intra-articular scapula fracture.

The inclusion criteria were:

1. Glenoid intra-articular fracture with displacement more than $2 \mathrm{~mm}$.

2. Patients with Gleno-polar angle more than 30 degrees.

3. Poly-trauma patients who need to be mobilized early.

Exclusion criteria were:

1. Displacement of articular surface less than $2 \mathrm{~mm}$.

2. Patients who did not give their consent.

3. Patients with severe head injury or debilitating injury who needed medical care first.

The most common cause of fracture glenoid was road traffic accident, followed by fall from height. Other causes are enlisted in Table 1.

Table 1. The Causes of Fractures

\begin{tabular}{lc}
\hline Cause & No. of Patients \\
\hline Road traffic accident & 11 \\
\hline Fall from height & 5 \\
\hline Train Accident & 3 \\
\hline Electrocution & 1 \\
\hline
\end{tabular}

Sixteen out of 20 patients had associated injuries, fracture ipsilateral clavicle was the most commonly associated injury, and other causes are enlisted in Table 2. Right scapula was affected more than left that is 12 in right scapula and 8 in left.
Table 2. Associated Injuries in the Patients

\begin{tabular}{lc}
\hline Associated Injury & No. of Patients \\
\hline Fracture clavicle & 7 \\
\hline Fracture ribs & 3 \\
Fracture ribs with hemothrorax/pneumothorax & 2 \\
Fracture ipsilateral femur & 1 \\
Floating shoulder & 2 \\
\hline Cervical spine injury & 1 \\
\hline
\end{tabular}

The most common type of fracture encountered was type $2 \mathrm{~A}$ according to Ideberg classification described in Table 3. All patients presented to the casualty department were subjected to thorough clinical examination and evaluation of fracture and associated injuries. The standard evaluation for the affected shoulder included a 40-degree posterior oblique radiograph, a 60-degree anterior oblique (scapular Y) radiograph, and an axillary radiograph. All patients were advised a chest radiograph (antero-posterior view) and cervical spine radiograph (antero-posterior and lateral view). If the fracture was not clearly defined on these plain radiographs, 3D computed tomography was advised in almost all the patients before going for fracture fixation to know the amount of displacement. The average amount of displacement was $6.5 \mathrm{~mm}$ ranging from 3 to $8 \mathrm{~mm}$. All displacements with intra-articular steps or gaps exceeding $2 \mathrm{~mm}$ or a glenoid-polar angle $>30$ degrees were considered indications for surgery. In patients with preoperative pneumothorax treated with chest drain insertion, the drain was kept in situ until the operation was completed. The patients were operated on once their conditions were stabilized. The duration between operation and admission ranged from 2 to 6 days (average of 3.5 days) surgical technique:

All the fractures were approached from posteriorly; the patient was positioned in lateral decubitus position with the arm in abduction. We followed an inverted U approach described by Abbott and Lucas, and then we made the skin incision $5 \mathrm{~cm}$ distal to the spine of the scapula at the junction of its middle and medial thirds, and extended it superiorly over the spine and laterally to the angle of the acromion. Afterwards, we curved the incision distally over the tendinous interval between the posterior and middle thirds of the deltoid muscle, and we freed the deltoid sub-periosteally from the spine of the scapula, then splitting it distally in the interval, and turning the resulting flap of skin and muscle distally for $5 \mathrm{~cm}$ to expose the infraspinatus and teres minor muscles and the quadrangular space. The posterior humeral circumflex artery and the axillary nerve each was divided into anterior and pos- 
terior branches, so while splitting of the deltoid between its posterior and middle thirds we took precaution not to injure them. Then we carried this division of the deltoid to its insertion to give full access to the quadrangular space whenever desired according to the fracture pattern. To expose the glenohumeral joint, we incised the shoulder cuff in its tendinous part, and divided the capsule. Fracture was visualized and reduced under direct vision of both the intra-articular and extra-articular aspects. The fragments were held temporarily in the reduced position with smalldiameter Steinmann pins or K wires. After articular reconstruction of glenoid fracture with a $4.5 \mathrm{~mm}$ lag screw, the stabilization of the intra-articular fracture was achieved using a $3.5 \mathrm{~mm}$ distal radius plate and extra-articular part was stabilized with a $2.7 \mathrm{~mm}$ Recon plate depending on the fracture type. To render adequate strength, in few cases $2.7 \mathrm{~mm}$ dynamic compression plates were used for fixation along the lateral border of the scapula. The longest plate was chosen for lateral border of scapula. The incision in the capsule of the shoulder was closed. The infraspinatus muscle was then repositioned in its fossa. Rotator cuff was repaired. The deltoid muscle was then sutured to the spine of the scapula. A suction drain was placed, and the skin wound was closed.

Table 3. Ideberg Classification

\begin{tabular}{|c|c|}
\hline Type & Extent \\
\hline I a & anterior rim fracture \\
\hline I b & posterior rim fracture \\
\hline II & $\begin{array}{l}\text { fracture line through the glenoid fossa exiting at the lateral scapular } \\
\text { border }\end{array}$ \\
\hline III & $\begin{array}{l}\text { fracture line through the glenoid fossa exiting at the superior } \\
\text { scapular border }\end{array}$ \\
\hline IV & $\begin{array}{l}\text { fracture line through the glenoid fossa exiting at the medial scapular } \\
\text { border }\end{array}$ \\
\hline $\mathbf{V a}$ & combination of types II and IV \\
\hline $\mathbf{V b}$ & combination of types III and IV \\
\hline V c & combination of types II, III, and IV \\
\hline VI & comminuted fracture \\
\hline
\end{tabular}

Table 4. Classification of the Fractures According to Ideberg's Classification (Ideberg, 1984)

\begin{tabular}{lc}
\hline Type of Fracture & No. of Patients \\
\hline $\mathbf{1}$ & 0 \\
$\mathbf{2}$ A-Transverse & 7 \\
\hline B - Oblique & 3 \\
$\mathbf{3}$ & 5 \\
$\mathbf{4}$ & 4 \\
$\mathbf{5}$ & $\mathbf{1}$ \\
\hline
\end{tabular}

Postoperatively, the shoulder was immobilized for 10 days. Passive mobilization of ipsilateral elbow and wrist was started in 10 days postoperatively and after 21 days passive and elastic strapping for strengthening exercises were started until movement of the affected shoulder becomes the same as that of the opposite shoulder or for minimum up to 7 weeks postoperatively. In cases with an associated clavicular, shoulder was immobilized with a Gilchrist sling used for few more days (up to 3 weeks). Postoperative and follow-up radiography included an AP view at 3-week and 6-week follow-up appointments.

\section{Results}

The patients were attended regularly in the out- patient department and were assessed using the scoring system suggested by Rowe (Rowe, 1988) and the ConstantMurley scale. Muscle power was assessed manually and compared with the opposite normal shoulder. In the patients of the present series, the osseous position obtained at the operation was maintained, and fracture-healing was judged to have occurred at an average of 3.5 months (range, 2 - 6 months) after the operation. The mean length of stay in hospital was 17 days (5 to 33) and the mean operating time was 150 minutes (100 to $280 \mathrm{~min}$ ).

\subsection{Follow-up}

We had a mean follow-up of 3 years, ranging from 8 months to 6 years. The outcome of the 20 fractures was determined using the Constant-Murley score evaluated starting at 4 weeks postoperative. Both shoulders were assessed and the score on the injured side was given as a percentage of that on the uninjured side. The median score was $88 \%$ (mean 65\%, range 30 to 100 ).

The median score for strength was 21/25 (mean 19, range 0 to 25 ) and that for pain $11 / 15$ (mean 11, range 5 to 15 ). The median functional score was $16 / 20$ (mean 15 , range 0 to 20). The mean range of active abduction of the shoulder was $135^{\circ}$ (20 to 180), the mean range of flexion $138^{\circ}$ (20 to 180 ) and the mean range of external rotation $38^{\circ}$ (0 to 100).Five patients showed excellent result; 11 patients showed good result; 3 patients showed fair result and one patient had poor outcome according to the Constant-Murley score.

According to the Rowe's scoring system, five patients had excellent result with a mean score of 92, eleven had good results with a mean score of 77 , three had fair result with a mean score of 60 , and one had poor result with the score of 38. That one patient with poor result had a postoperative step of $3 \mathrm{~mm}$ and the other 19 patients had an anatomical reduction. The previous patient developed osteoarthritis of shoulder within 4 years. The patient presented with few complaints and a Constant score of 74 points. 
The implants were not removed routinely. Radiographs showed no displacement of the articular surfaces and no evidence of migration or loosening of the screws or plates. The Rowe score and the Constant-Murley score of our patient were comparable.

Table 5. Results by the Constant-Murley and Rowe's Scores

\begin{tabular}{lccc}
\hline No. & Rowe's Score (100 pts) & $\begin{array}{c}\text { Constant-Murley Score } \\
(\mathbf{1 0 0 p t s})\end{array}$ & Valuation \\
\hline $\mathbf{1}$ & 80 & 81 & Good \\
$\mathbf{2}$ & 84 & 88 & Good \\
$\mathbf{3}$ & 66 & 72 & Fair \\
$\mathbf{4}$ & 78 & 80 & Good \\
\hline $\mathbf{5}$ & 92 & 95 & Excellent \\
$\mathbf{6}$ & 72 & 75 & Good \\
\hline $\mathbf{7}$ & 52 & 56 & Fair \\
$\mathbf{8}$ & 38 & 48 & Poor \\
\hline $\mathbf{9}$ & 90 & 98 & Excellent \\
$\mathbf{1 0}$ & 80 & 84 & Good \\
\hline $\mathbf{1 1}$ & 76 & 80 & Good \\
$\mathbf{1 2}$ & 86 & 92 & Excellent \\
\hline $\mathbf{1 3}$ & 62 & 64 & Fair \\
\hline $\mathbf{1 4}$ & 74 & 82 & Good \\
\hline $\mathbf{1 5}$ & 76 & 84 & Good \\
$\mathbf{1 6}$ & 72 & 78 & Good \\
\hline $\mathbf{1 7}$ & 98 & 100 & Excellent \\
$\mathbf{1 8}$ & 80 & 88 & Good \\
\hline $\mathbf{1 9}$ & 78 & 78 & Good \\
\hline $\mathbf{2 0}$ & 92 & 91 & Excellent \\
\hline & & & \\
\hline
\end{tabular}

\subsection{Complications}

Superficial infection occurred in few patients and got settled with antibiotics. One patient had delayed healing due to infection. One patient had stiffness of the shoulder at six weeks and manipulation under anesthesia was needed to make the joint more mobile; he had a follow-up score of $81 \%$.

\section{Discussion}

Conservative treatment is generally recommended for scapular fractures and surgical treatment is not commonly employed $(12,14,16)$. Several authors have, however, recommended operative treatment for displaced fractures, in order to reduce the incidence of posttraumatic arthritis of the shoulder in high demanding patients $(12,16,27)$. The results after open reduction and internal fixation of displaced intra-articular fractures of the glenoid using distal locking plate are reported by the authors. Aulicino et al. (16) described the findings in two patients with followup of 2 and 3 years respectively after operation; both had an excellent result. Hardegger et al. (12) have recorded

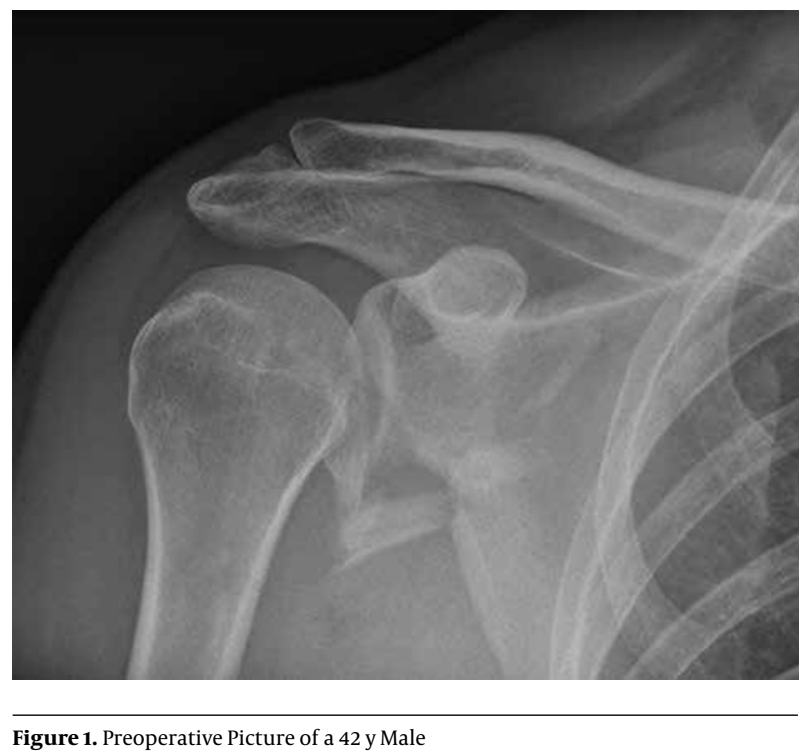

Figure 1. Preoperative Picture of a 42 y Male

the maximum number of patients treated surgically for fracture scapula, which included 12 involving the glenoid. They recommended reduction and fixation of incongruent fractures of the glenoid, but the results for displaced type of fractures were not separated from those from the total number of patients. Aston and Gregory (28) described three surgically treated fractures of the glenoid, which had been associated with dislocation of the shoulder. Kavanagh et al. (4) described ten fractures of the glenoid fixed through a posterior approach and the patient had good result but the author did not use any scoring system nor did he recorded any follow-up time. The largest series of fractures of the glenoid was reported by Leung et al. (18) with a mean follow-up of 30.5 months. They had good result in most of the patients using their own scoring system. Unfortunately they did not report any surgical complications. Wilber and Evans (14) described the conservative management of three displaced fractures of the glenoid from a series of 52 scapular fractures. They did not, however, record the displacement at the time of injury or after union of the fracture. In their series, two patients had fair result, with slight pain and loss of movement of less than $25 \%$; the third had a poor result with moderate pain and loss of both flexion and abduction of the shoulder of more than $25 \%$. These authors suggested immobilization of the arm in abduction, followed by physiotherapy, as a more aggressive form of treatment for intra-articular fractures of the glenoid. All the above authors did the fixation with either reconstruction plate, dynamic compression plate or cannulated cancellous screws, whereas in our series the fixation of glenoid rim was done with a distal radius plate for articular recon- 

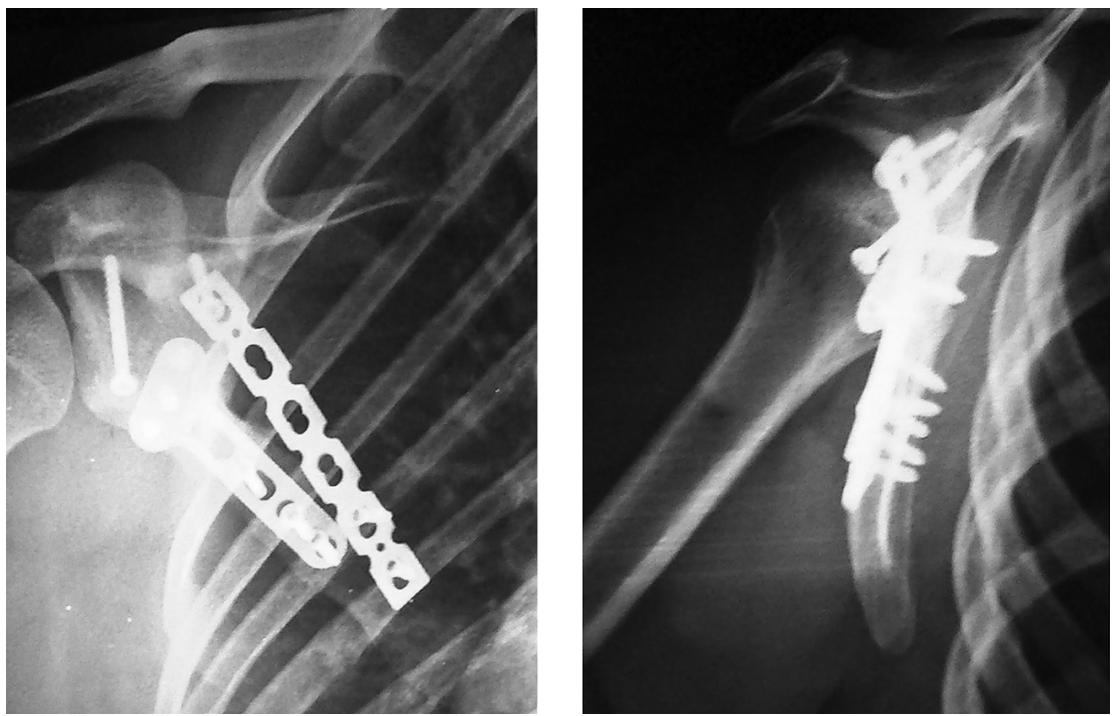

Figure 2. Post-Operative Picture of the Same Patient
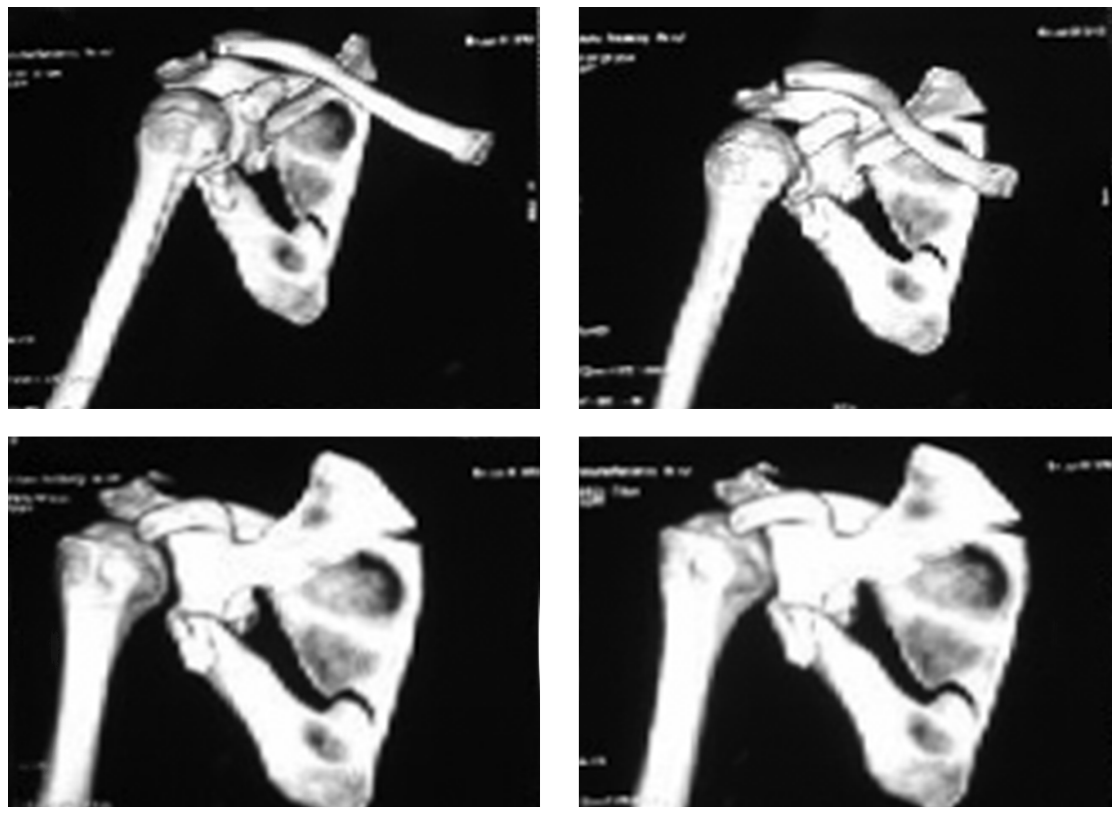

Figure 3. Preoperative CT Scan

struction with a trans-glenoid screw and had a good outcome. The rehabilitation was started early in our series and patient satisfaction was superior with a good functional outcome. The buttressing effect caused by the shape of the distal radius plate gave us better purchase and hold on the glenoid. Due to its superior hold we were able to start early mobilization of the affected shoulder leading to early re- turn of activity. To gain these benefits, we decided to use the distal radius plate.

The posterior operative approach described in the present report allowed excellent visualization of both the intra-articular and the extra-articular components of the fractures of the glenoid fossa. We do not advocate this approach for fractures limited to the anterior rim of the 


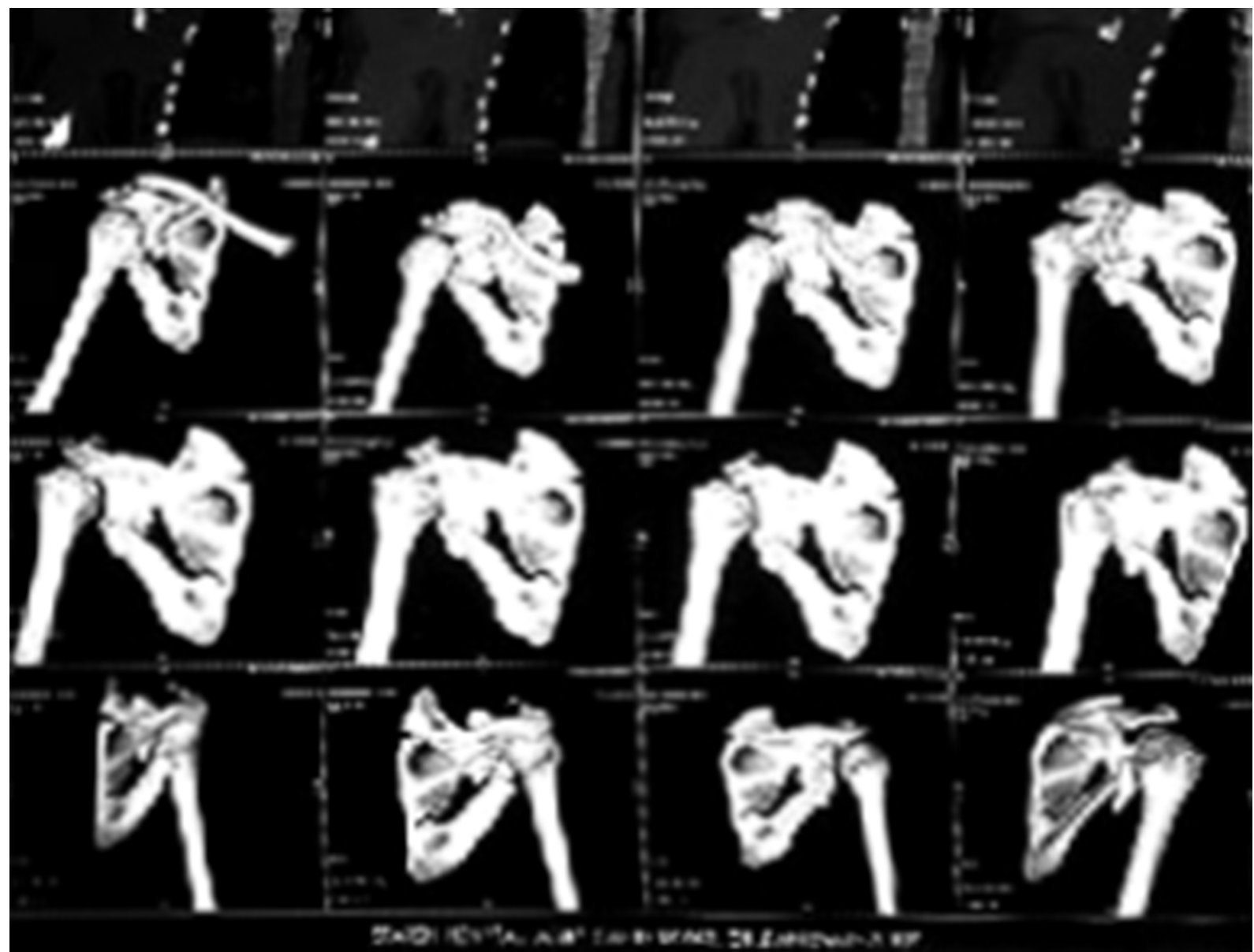

Figure 4. Preoperative CT Scan

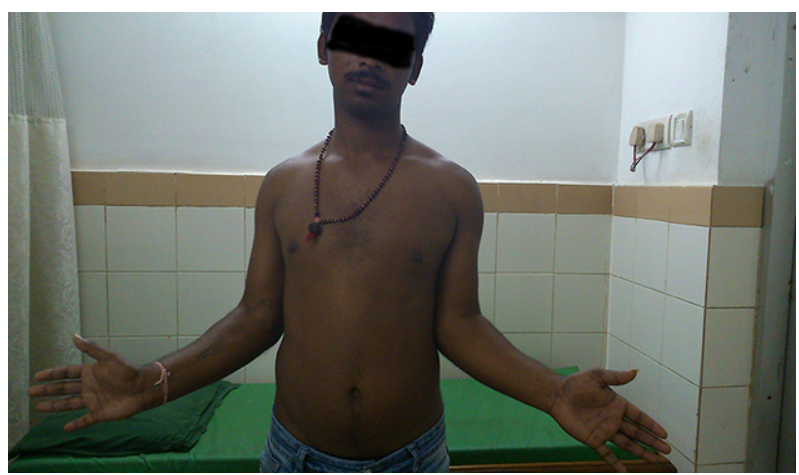

Figure 5. Range of Motion at Subsequent Visits

glenoid; however, for the transverse, vertical, and stellate fractures with minimum comminution that were sustained by the patients in this series, the approach allowed easy recognition and temporary and final fixation of the fracture. If these soft-tissue structures do not heal well, major weakness of external rotation of the shoulder or posterior instability of the joint may develop. Hence, we sutured back each and every muscle that was raised to its anatomical location which led us to have a better functional outcome. The patients in this series were all healthy, young or middle aged adults who wished to remain physically active. All had substantial displacement of the articular surfaces. We had good outcome in most of the patients; hence, this lead us to conclude that open reduction and internal fixation with the distal radius plate should be considered for patients who have articular displacement over $2 \mathrm{~mm}$ and wish to remain active.

\subsection{Conclusions}

Management of intra-articular fracture of scapula is of paramount importance. As chest injuries are common 


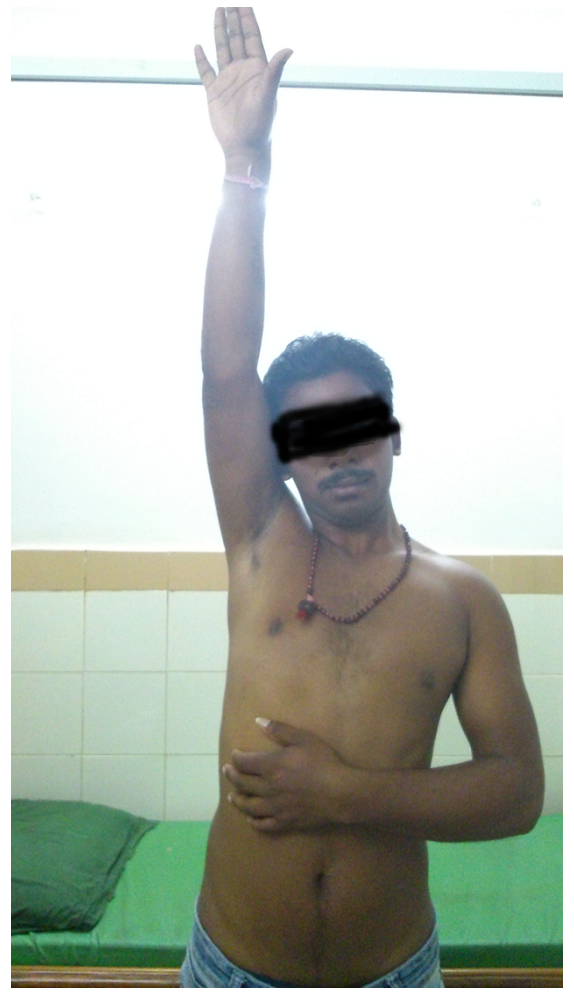

Figure 6. Range of Motion at Subsequent Visits

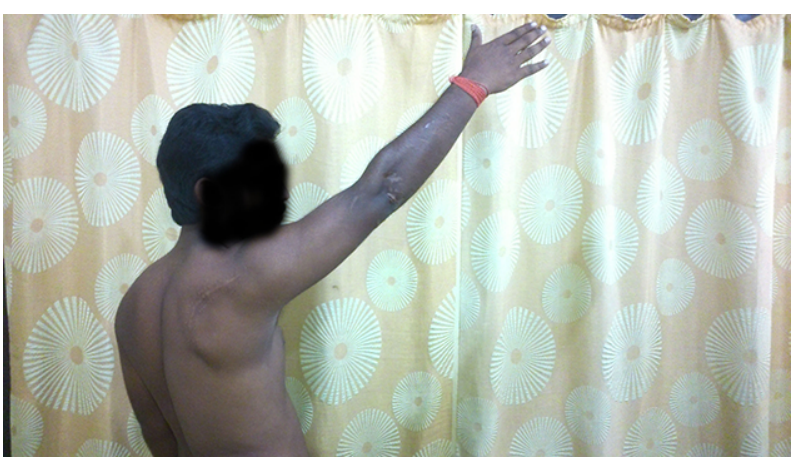

Figure 7. Range of Motion at Subsequent Visits

finding with scapula fracture, special attention must be given to treat them. Operative intervention is mandatory in displaced intra-articular fracture of scapula. Various fixation modalities have been described in the literature, however fixation of intra-articular fracture of glenoid with distal radius locking plate for articular reconstruction in the presented series provides good functional outcome that is better hold and buttressing effect on the glenoid rim with early restoration of the range of motion of the

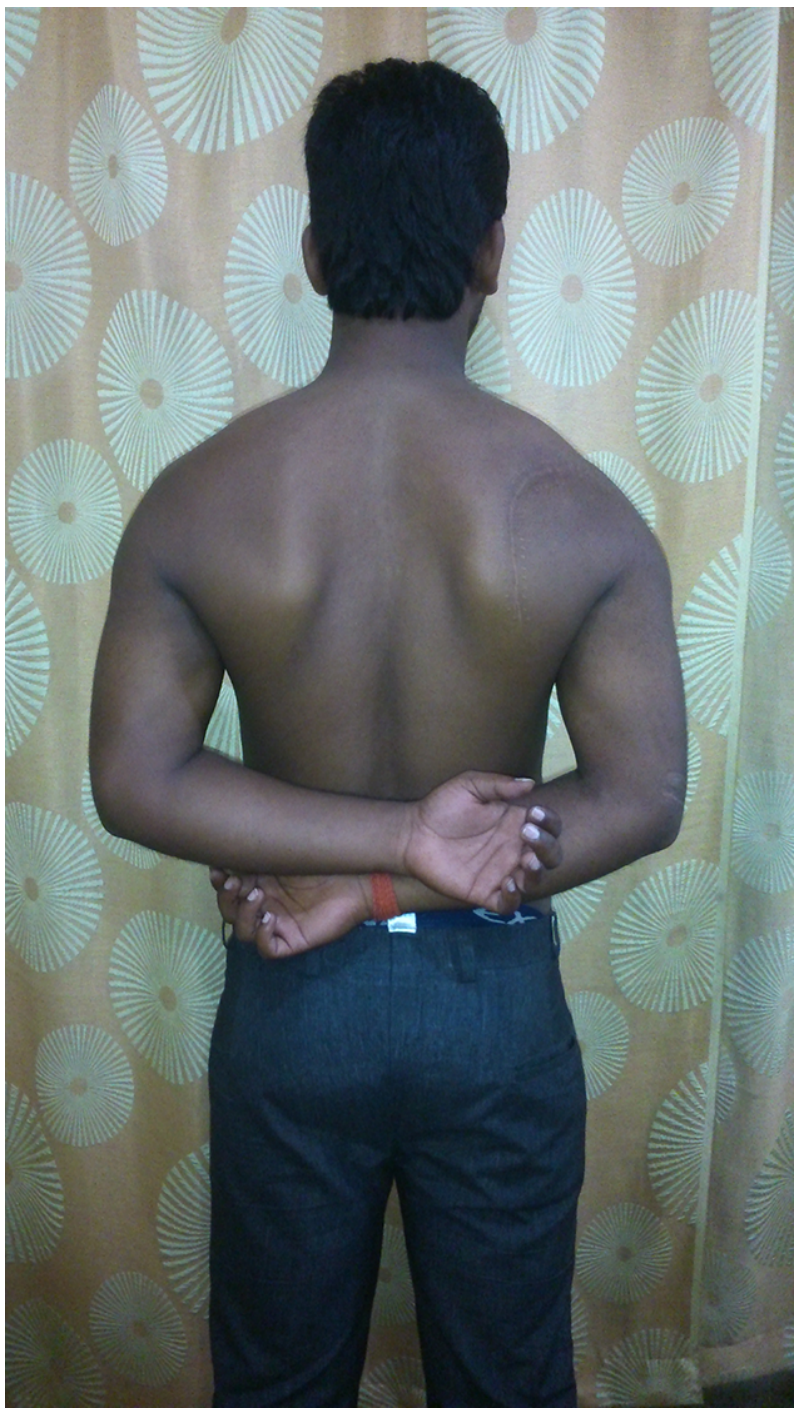

Figure 8. Range of Motion at Subsequent Visits

shoulder.

\section{Footnotes}

Authors' Contribution: Study concept and design: Ranajit Panigrahi; acquisition of data: Ranajit Panigrahi, and Divya Madharia; analysis and interpretation of data: Divya Madharia; drafting of the manuscript: Ranajit Panigrahi; critical revision of the manuscript for important intellectual content: Ranajit Panigrahi; statistical analysis: Saswat Samant, and Dibya Singha Das; administrative, technical, and material support: Ranajit Panigrahi, and Manas Ranjan Biswal; study supervision: Ranajit Panigrahi, and Manas Ranjan Biswal. 
Financial Disclosure: No benefits in any form have been received or will be received from a commercial party related directly or indirectly to the subject of this article.

Funding/Support: With the support and combine efforts of all the authors of this study.

\section{References}

1. Ada JR, Miller ME. Scapular fractures. Analysis of 113 cases. Clin Orthop Relat Res. 1991(269):174-80. [PubMed: 1864036].

2. Euler E, Habermeyer P, Kohler W, Schweiberer L. [Scapula fracturesclassification and differential therapy]. Orthopade. 1992;21(2):158-62. [PubMed: 1594236].

3. Ideberg R, Grevsten S, Larsson S. Epidemiology of scapular fractures. Incidence and classification of 338 fractures. Acta Orthop Scand. 1995;66(5):395-7. [PubMed: 7484114].

4. Kavanagh BF, Bradway JK, Cofield RH. Open reduction and internal fixation of displaced intra-articular fractures of the glenoid fossa.J Bone Joint Surg Am. 1993;75(4):479-84. [PubMed: 8478375].

5. McGinnis M, Denton JR. Fractures of the scapula: a retrospective study of 40 fractured scapulae. J Trauma. 1989;29(11):1488-93. [PubMed: 2685337].

6. Nordqvist A, Petersson C. Fracture of the body, neck, or spine of the scapula. A long-term follow-up study. Clin Orthop Relat Res. 1992(283):139-44. [PubMed: 1395237].

7. Adam FF. Surgical treatment of displaced fractures of the glenoid cavity. Int Orthop. 2002;26(3):150-3. doi: 10.1007/s00264-002-0342-8. [PubMed: 12073106].

8. McGahan JP, Mc Gahan GT, Rab A. Dublin Fractures of the scapula. J Trauma. 1980;20:88.

9. Rowe CR. Fractures of the Scapula. Surg Clin North Am. 1963;43:1565-71. [PubMed:14090204].

10. Rowe CR. The Shoulder. New York: Churchill Livingstone; 1988. p. 631.

11. Findlay RT. Findlay Fractures of the scapula and ribs. Am J Surg. 1937;XXXVIII:489.

12. Hardegger FH, Simpson LA, Weber BG. The operative treatment of scapular fractures. J Bone Joint Surg Br. 1984;66(5):725-31. [PubMed: 6501369].

13. Imatani RJ. Fractures of the scapula: a review of 53 fractures. JTrauma. 1975;15(6):473-8. [PubMed: 1127777].

14. Wilber MC, Evans EB. Fractures of the scapula. An analysis of forty cases and a review of the literature. J Bone Joint Surg Am. 1977;59(3):358-62. [PubMed: 849947].
15. Zdravkovic D, Damholt VV. Comminuted and severely displaced fractures of the scapula. Acta Orthop Scand. 1974;45(1):60-5. [PubMed: 4451053].

16. Aulicino PL, Reinert C, Kornberg M, Williamson S. Displaced intraarticular glenoid fractures treated by open reduction and internal fixation.J Trauma. 1986;26(12):1137-41. [PubMed: 3795314].

17. Harmon PH, Baker DR. Fracture of the scapula with displacement. J Bone Joint Surg. 1943;25:834-8.

18. Leung KS, Lam TP. Open reduction and internal fixation of ipsilateral fractures of the scapular neck and clavicle. J Bone Joint Surg Am. 1993;75(7):1015-8. [PubMed: 8335660].

19. Rikli D, Regazzoni P, Renner N. The unstable shoulder girdle: early functional treatment utilizing open reduction and internal fixation. J Orthop Trauma. 1995;9(2):93-7. [PubMed: 7776042].

20. Hashiguchi $\mathrm{H}$, Ito $\mathrm{H}$. Clinical outcome of the treatment of float ing shoulder by osteosynthesis for clavicular fracture alone. J Shoulder Elbow Surg. 2003;12(6):589-91. doi: 10.1016/S1058274603001794. [PubMed: 14671523].

21. Herrera DA, Anavian J, Tarkin IS, Armitage BA, Schroder LK, Cole PA Delayed operative management of fractures of the scapula. $J$ Bone Joint Surg Br. 2009;91(5):619-26. doi: 10.1302/0301-620X.91B5.22158. [PubMed: 19407296].

22. Jones CB, Cornelius JP, Sietsema DL, Ringler JR, Endres TJ. Modified Judet approach and minifragment fixation of scapular body and glenoid neck fractures. J Orthop Trauma. 2009;23(8):558-64. doi 10.1097/BOT.0b013e3181a18216. [PubMed:19704270].

23. Goss TP. Fractures of the glenoid cavity. J Bone Joint Surg Am. 1992;74(2):299-305. [PubMed: 1541626].

24. Mayo KA, Benirschke SK, Mast JW. Displaced fractures of the glenoid fossa. Results of open reduction and internal fixation. Clin Orthop Relat Res. 1998(347):122-30. [PubMed: 9520882].

25. Cole PA. Scapula fractures: open reduction internal fixation. 2 ed. Philadelphia: Lippincott Williams \& Wilkins; 2006. pp. 15-36.

26. van Noort A, te Slaa RL, Marti RK, van der Werken C. The floating shoulder. A multicentre study. J Bone Joint Surg Br. 2001;83(6):795-8. [PubMed: 11521916]

27. Terbruggen D, Muller J, Skutella E. [Osteosynthesis of scapular fractures within the scope of multiple injuries of the shoulder girdle]. Hefte Unfallheilkd. 1975(126):62-3. [PubMed: 1234283].

28. Aston JW, Gregory CF. Dislocation of the shoulder with significant fracture of the glenoid.JBone Joint Surg Am. 1973;55(7):1531-3. [PubMed 4758724]. 